\title{
The Application of Biomimetics and Architectural Skin as a Sustainable Strategy
}

Francisco Xavier Martínez Rodríguez ${ }^{1}$; Níckolas Alfredo Bernal Ramirez ${ }^{2}$ \& Ana Cristina García Luna Romero ${ }^{3}$

${ }^{1}$ Universidad de Monterrey, San Pedro Garza García, N.L, México

${ }^{2}$ Universidad de Monterrey, San Pedro Garza García, N.L, México

${ }^{3}$ Universidad de Monterrey, San Pedro Garza García, N.L, México

\begin{abstract}
The relationship between biomimetics as a design strategy and architectural skin as a construction technique, both of these strategies can be implemented in a building design process to develop more sustainable project, now a days there is a pollution problem in Mexico and one of the main causes is the waste generated by construction, in addition, just a few investors are interested in the application of bioclimatic strategies, sustainable technologies and building materials because they imply a large investment and constant maintenance, which is why an architectural skin designed based on the responsive skin of the crocodile is proposed, which is expected to be seen as a model for future generations of Mexican architects for them to implement these strategies and methodologies in their design process.
\end{abstract}

${ }^{\text {I} F r a n c i s c o ~ X a v i e r ~ M a r t i ́ n e z ~ R o d r i ́ g u e z: ~ f r a n c i s c o x . m a r t i n e z @ u d e m . e d u ~}$

${ }^{2}$ Nickolas Alfredo Bernal Ramirez: nickolas.bernal@udem.edu

${ }^{3}$ Ana Cristina García Luna Romero: anacristina.garcialuna@gmail.com 


\section{Introduction}

According to Enshasi; Kochendoerfer \& Rizq [1] Excessive construction, without good planning, and its waste is the main cause of environmental pollution. Building design with appropriate strategies and good analysis can have an impact and reduce pollutants in the country.

Nowadays, the need for adaptability has always been the primary task of mankind. It stems from the consciousness of survival. As Escolano [2] mentioned, in the history of architectural design, the use of shutters, doors, windows, walls and doors has become an element. Has implemented and established isolation between the user and the environment.

At the same time, as mentioned by Arribas [3] Over the years, different strategies and technologies have been implemented in the design that benefit in the exploration for a more sustainable architecture, and thus improve adaptability to its environment.

When solving a design problem from a bioclimatic perspective, Arribas [3] defines it as the result of an environmental analysis performed in the planned construction area, which defines the method by which appropriate passive systems will be used. Applied to buildings.

In the same way, as Arribas [3] stated in the search for new sustainable development strategies that can be used in buildings, the concept of "animal architecture" emerged. As defined by the concept's name, this type of building Focusing on buildings created by different types of animals (such as nests and caves), they have been used as imitation objects in architectural design.

As Salas mentioned; Bedoya \& Argilés [4]; When it is sought to design a building that responds to environmental threats in the same way as nature, other foundations of design are more important than nature itself. Comparing two important concepts used in architectural design, the first concept mentioned is "biomorphology", which is only an attempt to imitate the aesthetic factors found in plant and animal species in nature. The other concept is "biomimetics". "It not only imitates form but it also focuses on the functional part of nature.

It is possible that the use of architectural skins unified to design based on biomimicry could be a technique that helps reduce environmental problems generated by construction and that it could also be part of the new innovations that are introduced in Mexico.

In order to introduce these technologies to Mexico, a responsive skin based on nature was proposed. This architectural element can be used as a research case to help future generations the needs of the people in the building.

\section{Design Guiding Axis}

Now, for the design of architectural responsive skin, some concepts are used, the most important of which is the aesthetic and functional inspiration of elements found in nature. As mentioned before, it is bionics and also sustainable. Guiding Principles. The design is used, and it also governs other realized concepts.

\subsection{Responsive Skins}

First of all, it is important to ask yourself why the environmental and economic expenditures of active air conditioning systems in "modern" buildings are so high. This is due to solar events and the lack of ventilation in high-rise buildings that use curtain walls and maintain direct contact with the outside world.

Therefore, when designing, it is necessary to have a good understanding of what is responsive skin to understand why it is necessary to introduce this technology as a new method of sustainable innovation. Escolano [2] defines the concept as a set of elements. Buildings are not directly in contact with the outside materials; therefore, materials and mechanisms must be considered to protect them from various climatic conditions.

\subsection{Sustainable Design}

In order to design a building appearance that does not isolate human buildings from the environment but integrates them, it is necessary to consider various factors; as Hernández [5] mentioned, this type of architecture aims to reduce the The cost of using natural resources is also trying to reduce water, soil and air pollution, and to provide maximum comfort for the users who come into contact with the interior and exterior spaces of the building.

Similarly, Hernández [5] mentioned that in the construction process, the choice of materials is extremely important, and the quantity and quality of the materials must be considered. If carefully planned, this will help reduce the possible waste of the building. Likewise, this particular process of selecting materials may reduce economic expenditures, thereby increasing the durability of the building.

It should also be noted that this concept of sustainable design covers a wide variety of issues, two of which are also considered for the design of building 
skins are based on the design of bioclimatic buildings and the use of passive climate systems.

\subsubsection{Bioclimatic Architecture}

Designing from the perspective of bioclimatic buildings is directly related to the implementation of sustainable design. As D'Amico [6] mentioned, there are three types of buildings that try to implement this design strategy. The first type only aims to achieve high energy efficiency; the second type not only focuses on the implementation strategies of the built buildings, but also tries to apply sustainable design strategies from the initial process of the building to the possible deconstruction itself. The third type of buildings not only focuses on improving the internal expenditure efficiency of the building, but also takes into account the efficiency of its surrounding environment, focusing on issues such as landscape, water collection and mainly user comfort.

It should also be added that in the design strategy mentioned by Winitzky [7], three types of air-conditioning systems can be applied: passive, active and hybrid to produce the desired comfort. Active systems refer to components that require current to function and generate the comfort; hybrid systems are systems that use active and passive strategies at the same time; and finally, passive climate strategies are used to design the outer skin of the building.

\subsubsection{Passive Climate Systems}

When referring to the concept of sustainable buildings, it is important to know that one of the strategies that can be applied to buildings is the design based on passive climate systems. As mentioned by Winitzky [7], buildings using this type of system focus on trying to reduce energy use and try to create indoor comfort for users through building design rather than electronic means.

As shown in figure 1 The only method that is applied in the house is the position of openings in the walls, this to allow the natural flow of ventilation and light's entrance at the same the use of vegetation near the house, the modification in topography and a small slab extension on the house's entry is used to generate shadows and protect the user form bad climate timing without the waste of electricity.

Figure 1. Passive system applied into architectural design

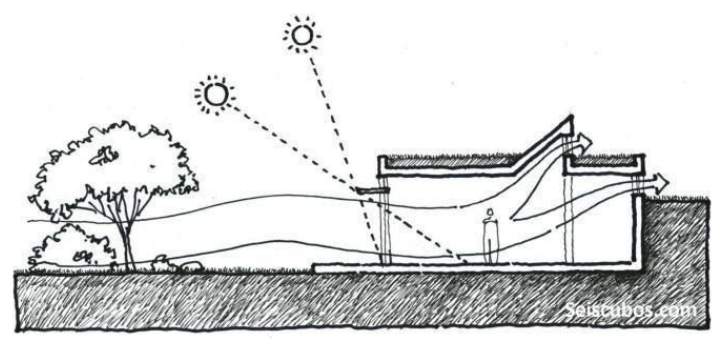

Similarly, Winitzky [7] mentioned that an important feature when designing with passive systems is that the structure and location of the building are within the terrain, and the location of windows and corridors will determine the light and heat input. Ventilation to create comfort inside and outside the building.

When designing the exterior of the building, it is necessary to integrate the second-story facade to control the environmental comfort of the users living indoors. This means that the use of the location of the building is conducive to taking advantage of the advantages of sunlight in cold winters and natural ventilation in high temperatures in summer day.

\subsection{Biomimetics}

It is important to define biomimetics, according to Rangel; Rodríguez; Martínez \& Hernández [8] the same word explains their concept "Bio" means life and "mimesis" imitate, likewise Petraglia [9] adds that the way in which nature can be related to architecture is because it is a factor that changes and adapts to the environment just as buildings should, in the designed skin, it is sought that with the materiality and the same functional design it can be able to integrate into the nearby space and the city itself.

It's also important to add that López; Rubio; Martín \& Croxford [10] state that there is a direct relationship with nature and climate since temperature is one of the main factors that causes living things to evolve, for example plants and animals over the years began to develop qualities which protect them and help them survive under high and low temperatures

Now, according to Zari [11], bionics can be viewed from five different perspectives. Architects can imitate shapes or geometric shapes, characteristics of materials, processes of natural systems, functions and even the construction process itself, imitating what is naturally produced Structure or pattern.

There is no doubt that the skin in a building designed with a bionic concept can also try to imitate the same function as human skin. As Baixas [12] mentioned, the main function of human skin is to regulate the interaction with the environment. After the discovery of the concept of bionics, the exterior wall began to be regarded as a protector, trying to break the "modern" culture, that is, to design these high-rise 
buildings with glass exterior walls and full permeability to the environment.

When considering bioclimatic strategies, it is important to consider that the solar incidence and wind that interact with these "modern" glass buildings are not regulated. One of the principles of sustainable design strategy is to seek a comfortable environment. Users, this is why the installation of a second façade as a filter can help reduce the economic loss of using these facilities during the high temperatures in Mexico.

\subsubsection{Biomimetics Applied in Architecture}

Currently there are buildings which have used biomimetics as a strategy in the design of their facades which respond to the environmental characteristics of the area in which they are being built, in addition they have been shown to be effective and functional in reducing economic costs due to the bioclimatic strategies applied.

Such is the case of the Swiss RE Tower, designed by Norman Foster, built in 2003 in London, England; López-Maroto [13] mentions that this building was inspired by the aesthetics and functionality of the Venus flower basket sponge.

Figure 2. Comparison between the Swiss RE Tower by Norman Foster and the Venus Flower Basket Sponge

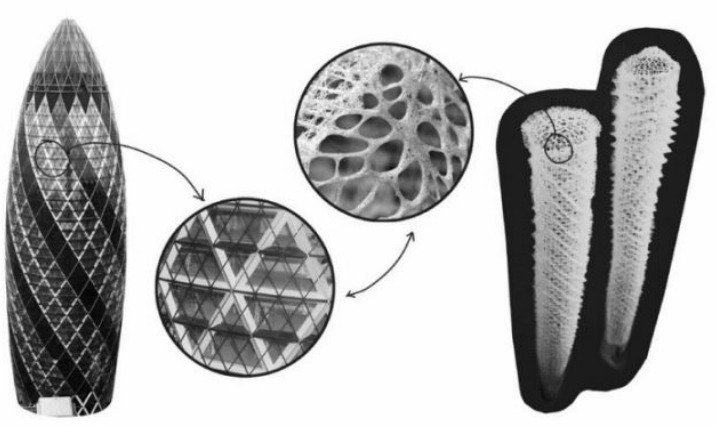

Regarding the characteristics of sponge, López-Maroto [13] mentioned that it is made of skeleton silica gel mesh. Due to its geometric shape, it has greater rigidity to resist water flow. These functions can also be realized as shown in Figure 2. The design of the Swiss RE Tower is the same as the surrounding structure, making the building resistant to wind without any internal reinforcement and allowing air to enter the building.

Another case study worth mentioning is the Eastgate Center established by Mick Pearce + Arup Associates in Harare, Zimbabwe in 1996. Dabija [14] mentioned how these architects started to discover the need for energy saving and then analyzed, they were able to observe how African termite buildings managed to protect them from the high and low temperatures in Zimbabwe.

Figure 3. Convection current inside Eastgate Center by Mick Pearce + Arup Associates

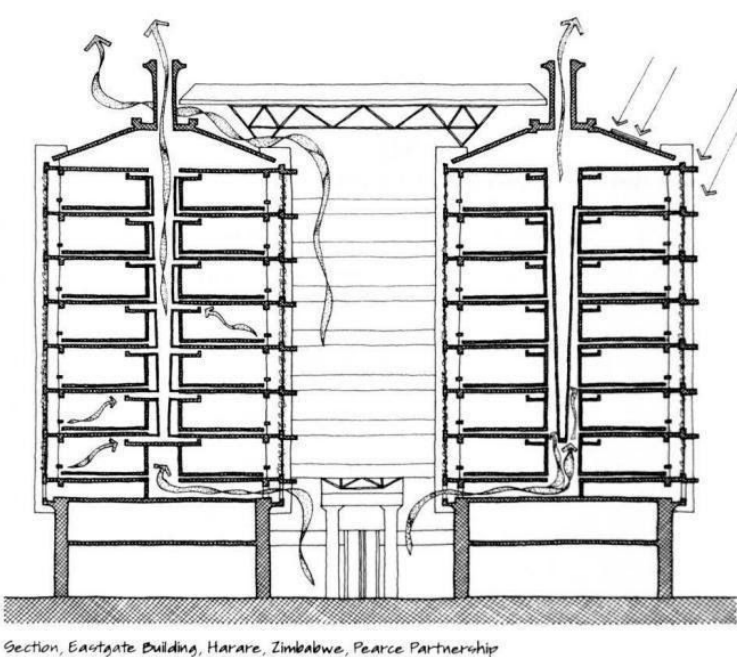

Regarding the quality used, Dabija [14] mentioned how termites produce holes that have the function of regulating internal temperature. Some of them inject hot air into the mound, while others expel them until they cover and create new orifices. That day. Convection is generated, as shown in Figure 3. This technology is used in the design of the Eastgate Center to create interior comfort in the interior area of the building.

\section{Designed Architectural Skin}

After analyzing the natural skin of different types of animals, it is concluded that the crocodile uses its skin to survive in environments exposed to different temperatures during the day and night. According to its behavior, it can be concluded that it may be used to imitate its functions and The aesthetics of the new design.

First, as Uriarte [15] mentioned, crocodiles use their skin to adapt to the environment, and their behavior at different temperatures can help them survive. For example, in the sun during the day, the scales help absorb heat, and at night. It uses stored substances to survive the low temperature of the water bodies in which they live.

Figure 4. Osteoderms "flexible plates" in crocodile 


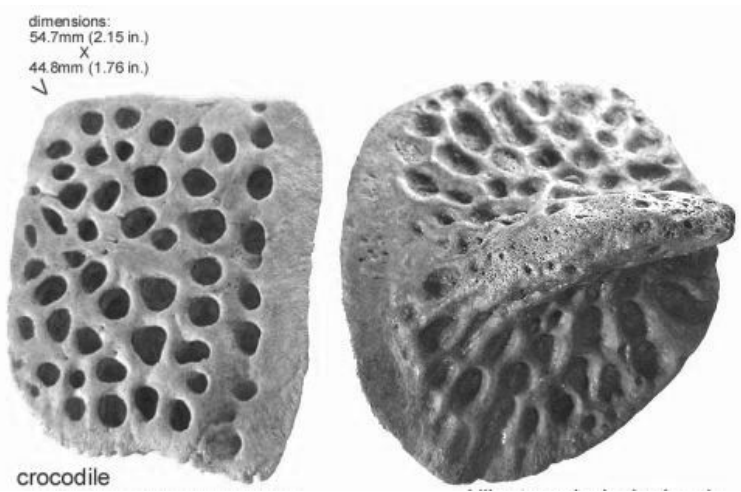

In addition, the crocodile also has two protective layers, one layer is harder and is exposed to the environment on the upper part for self-defense, the other layer is more flexible and stronger, and the following is composed of a bone plate called "bone skin". The bony dermis of Chen, WenYang \& Meyers [16] is shallow and porous, as shown in Figure 5, and its main function is to absorb heat. Animals use them as "solar panels" to regulate body temperature.

Figure 5. Hard Crocodile's Visible Skin

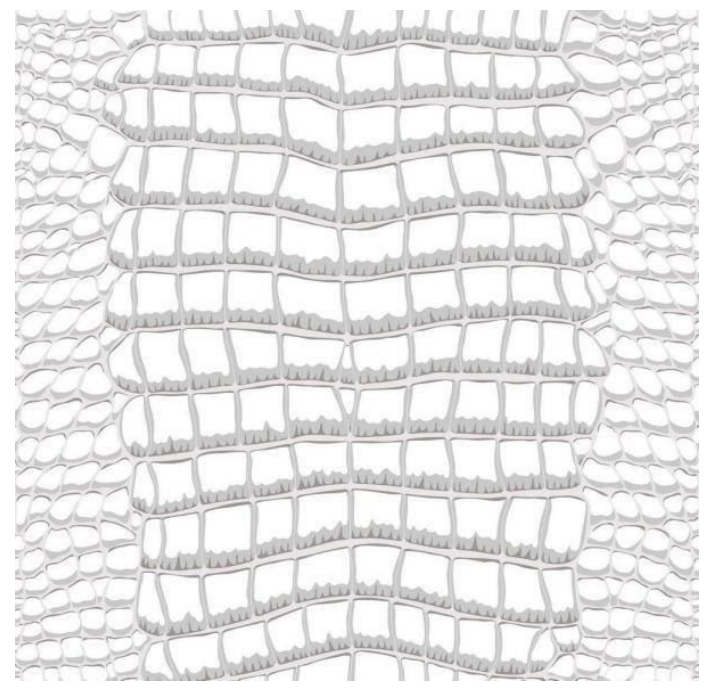

Now, in comparison to architecture, the first thing that was found interesting is their skin behavior which could be compared to how an architectural skin actually works, the reptile has two skins or, applied in a design process, they could be called "facades" that can be used as a bioclimatic strategy, one of these skins, as shown in figure 6 , is harder and more resistant, this would be the purpose of the second facade and the inner layer composed of osteoderms is more porous and fragile, which can be related to the curtain wall which would be protected by the responsive designed skin.

Figure 6. Skin pattern, aesthetic analysis.

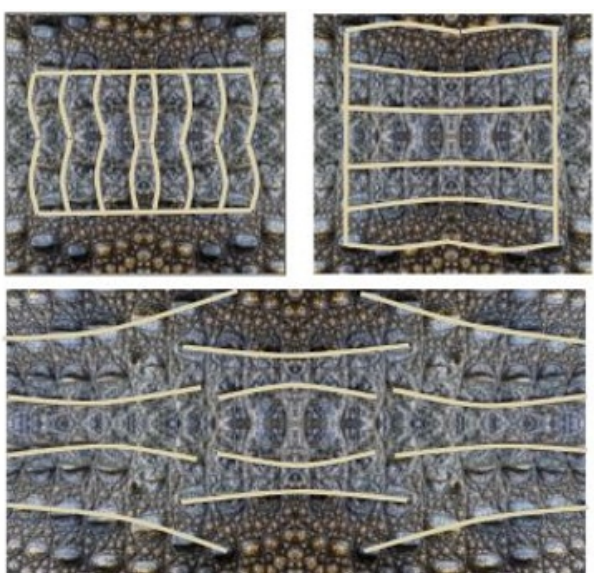

After considering the functional factors of animal skin, a method was sought to establish an aesthetic relationship based on the fractal of crocodile and the pattern produced by nature on its skin. As shown in figure 7, crocodile has different patterns. This is due to It is caused by the proportions on the visible surface, some of which are more elongated in the center, displayed as different superimposed layers, while other shorter proportions are displayed in the horizontal direction, which takes into account the central pattern building used in the design the process of skin.

\section{Skin Design Results}

Once the research object (in this case, the crocodile skin) was analyzed, the model established to seek to achieve the characteristics of the skin response, whether it is the bone layer of the dermis or the hard layer of the scales, the designed architectural skin will have to be covered The glass layer is used to produce changes in indoor comfort. In addition, in the bionic concept, people try to generate sustainable and effective forms in the design, adapt the form to its function and generate human-based solutions.

Figure 7. Architectural responsive skin

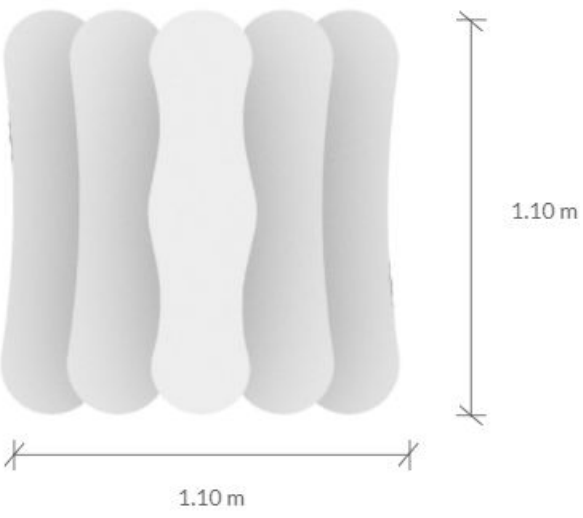




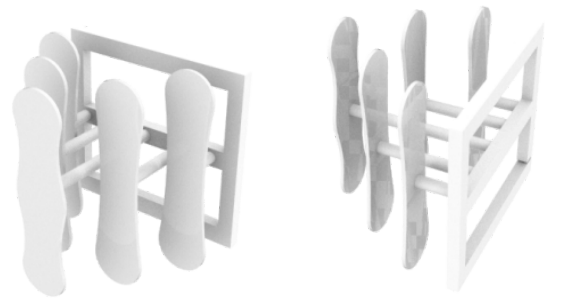

\subsection{Sustainable design applied to the skin}

Based on the above-mentioned concept of bionics, the concept of skin is planned to be closely related to sustainable design. As Hernandez [5] mentioned, to achieve the best and sustainable design, certain aspects must be considered in the creation process, such as Thermal comfort, air volume, terrain, energy and water consumption, and choice of materials and waste generated.

Like bionic devices, both concepts try to meet the needs of users. This kind of comfort not only appears in indoors trying to regulate temperature and air volume, but also in outdoor and urban scales because they help reduce pollution factors.

As mentioned earlier, the choice of materials is one of the most important factors in reducing the damage caused by the building to the environment. The use of concrete sounds like a high-waste material, but it is one of the local materials in Mexico, which reduces transportation. And the economic and environmental damage caused by the disposal process and have tried to use it correctly on the facade.

Similarly, for the analysis of reptile skin, it was decided to use glass for the internal and external walls. This glass will be protected by a second skin, thus simulating a fragile, "porous" and permeable "layer", which is Finger bone.

\subsubsection{Material applied to the architectural skin}

Once the building materials are determined, it is necessary to analyze the new materials used in the building, because the material of the skin needs to be determined, it must be lightweight, but at the same time hard, this is due to the comparison of the functions of the crocodile protection ruler.

As mentioned by Froeschle [17], in order for a material to be considered sustainable, it must have the following characteristics: First, the material must be energy efficient, and it must also be durable and renewable to prevent any form of damage Or harm. The ecosystem must be analyzed so that it will not produce substances harmful to the environment or endangering the health of users during its life cycle.
Finally, it is necessary to choose a material function method that does not produce waste and can be reused in any form.

Currently in European countries, cork is beginning to be implemented as a sustainable construction material, as mentioned by Merino [18], cork has various characteristics that make it a resistant and optimal material for facades, the material is $100 \%$ natural and recyclable, it is waterproof, breathable, light, non-flammable and it also has benefits as an acoustic insulation, the appearance can be modified with ecological dyes, it is resistant to pressure and compression

Finally it is related to the characteristics of the reptile, according Merino [18] cork can be used as a thermal insulator just as the crocodile skin does, the interior temperatures in the applied spaces regulated, likewise the skin seems to implement the use of solar cells, this generating the absorption of heat trying to emulate the bone layer of the animal.

Figure 8. Visualization of applied skin on facade

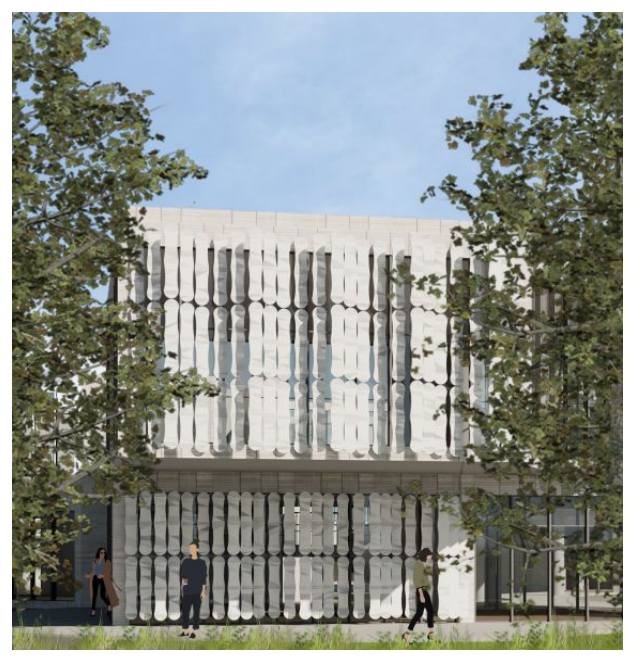

Figure 9. Section of building with Architectural skin applied

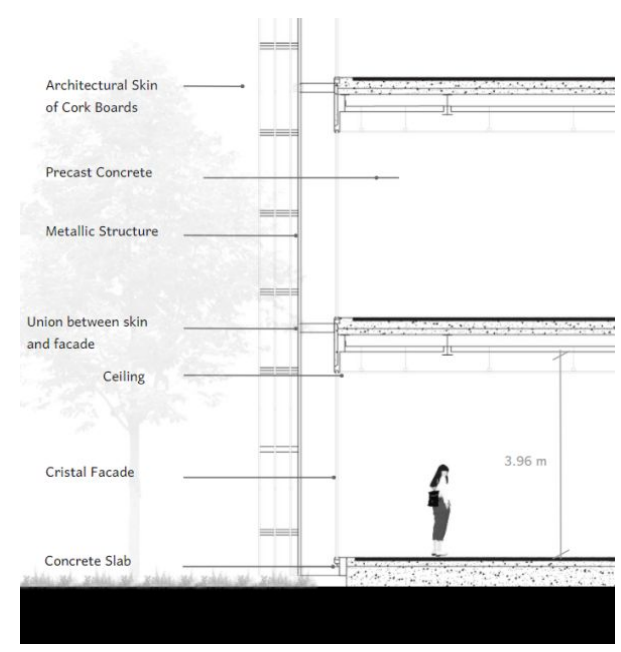


As shown in figure 8, the architectural skin manages to emulate the aesthetic properties of the crocodile, as mentioned before, for the second facade an investigation was carried out to select a material which will not cause severe damage to the environment that is why the cork was applied as the main material.

In the same way, as shown in figure 9, the responsive skin manages to protect the glass facade from interactions with the environment, however, it does not completely segregate the entry of light due to the same unevenness designed in the skin, a metallic structure is used to support the cork skin because a fragile material needs to be resistant to external threats.

\section{Conclusions}

In conclusion, Mexico has the potential to apply the development of new sustainable technologies in the design of its buildings; biomimetics and architectural skins as Zari [11] state, they provide a functional, aesthetic and economical solution for the user's comfort, it has also been proven that designing based on a system that benefits the environment not only solve problems at the scale of the people who interact directly with building but causes city-scale improvements

Just like Enshahi; Kochendoerfer \& Rizq [1] mentioned that logically, if architects continue to build buildings in an excessive way without planning, using the same technology and resources as nature, a goal will be achieved. Even if it is sustainable, it is difficult to come up with pollution solutions.

In addition, in the search for architects seeking to achieve the desired comfort level, they will end the comfort level of humans in the same city. It should also be considered that solving the problem on the scale of a single building will be regarded as a model that can be replicated. With the passage of time, cities can obtain larger-scale results.

Just as the crocodile uses its skin to protect the environment, there are many other animals with skins and scales that can be used for bioclimatic analysis, as mentioned by López-Maroto [13] and Dabija [14] the African termite and the Venus flower basket sponge have been elements of nature, of which their analysis and application goes beyond a simple aesthetic emulation due to the fact that multiple components are taken into account such as structure, materials and functionality.

Finally, it should be added that as mentioned by Baixas [12] the purpose of the strategy of imitation of nature and sustainable architecture is based on fully satisfying the needs generated by human beings, they do so with an environmental vision that can reduce the amount of pollutants generated during the process of construction.

\section{References}

1. Enshassi, A.; Kochendoerfer, B. \& Rizq, E. (2014) "Evaluación de los impactos medioambientales de los proyectos de construcción”. Rev. ing. constr. [online]. vol.29, n.3, pp.234-254. https://scielo.conicyt.cl/scielo.php?script=sci arttext\&pi $\mathrm{d}=\mathrm{S} 0718-$

2. Escolano, D. (2018) "Sistemas De Protección Solar Dinámicos". de:

https://upcommons.upc.edu/bitstream/handle/2117/1910 82/SISTEMAS $\% 20$ DE $\% 20$ PROTECCIO $\%$ cc $\% 81$ N $\% 2$ 0SOLAR $\% 20$ DINA \%cc\%81MICOS\%20-\%20DIEGO $\% 20$ ESCOLANO $\% 20$ FARTO.pdf? sequence $=1 \&$ is 11 lo $\underline{\text { wed }=\mathrm{y}}$

3. Arribas, J. (2015) "La arquitectura animal y sus sistemas de climatización pasiva como alternativa en el diseño arquitectónico" de:

http://zaloamati.azc.uam.mx/handle/11191/5995

4. Salas, C.; Bedoya, C.; Argilés, J. M.(2018) ”Antonio Gaudí, precursor de la sostenibilidad y la biomimética en la arquitectura, con 100 años de antelación" En: ACE: Architecture, City and Environment :Arquitectura, Ciudad y Entorno, 13 (37): 71-98 de: DOI: http://dx.doi.org/10.5821/ace.13.37.5348

5. Hernández, S. (2012) "El Diseño Sustentable como Herramienta para el Desarrollo de la Arquitectura y Edificación en México". de:

http://repositorio.ugto.mx/handle/20.500.12059/1020

6. D’Amico, C. (2000) "Arquitectura bioclimática, conceptos básicos y panorama actual". de: $\underline{\text { http://polired.upm.es/index.php/boletincfs/article/view/2 }}$ $\underline{270 / 2352}$

7. Winitzky, C. (2013) "Herramientas de diseño para una arquitectura sustentable". de:

http://repositorio.ub.edu.ar/handle/123456789/1582

8. Rocha Rangel, Enrique; Rodríguez García, José Amparo; Martínez Peña, Enrique, \& López Hernández, Juan (2012). "Biomimética: innovación sustentable inspirada por la naturaleza. Investigación y Ciencia", 20(55),56-61. ISSN: 1665-4412. (pg.1)

https://investigacion.uaa.mx/RevistalyC/archivo/revista 55/Articulo\%207.pdf

9. Petraglia, L. (2018). "Innovaciones en la biomimética. Envolventes dinámicas.” (pg. 98) https://revistas.unne.edu.ar/index.php/arq/article/view/4 201/3848

10. López, M.; Rubio, R.; Martín, S. \& Croxford, B (2017) "How plants inspire façades. From plants to architecture: Biomimetic principles for the development of adaptive architectural envelopes" de:

https://www.sciencedirect.com/science/article/abs/pii/S1 $\underline{36403211630510 X}$

11. Zari, M. (2007) "Biomimetic approaches to architectural design for increased sustainability". de:

https://d1wqtxts1xzle7.cloudfront.net/35781420/033-PE DERSENZARI.pdf?1417357384=\&response-content-di sposition $=$ inline $\% 3 \mathrm{~B}+$ filename $\% 3 \mathrm{DBiomimetic}$ approa ches to architectural d.pdf\&Expires $=1606901736 \&$ Sig nature $=\mathrm{GWWx} 4 \mathrm{~A}-0 \mathrm{nV} 4 \mathrm{WeTKnw} \sim \mathrm{wXFXMg} 2 \mathrm{Zk} \sim$ vjik 
y3PZn7CTKcbYsUE4VOFEEWOh1wzMXa5W7LL6ut 9MZvjLwZdq0iD nUd1oqTLJ08K-ViBOc-b1-qWMzbt ZR6gsfeJ6ZryoTeJ8aYR3PUqvigSB 8Uf26MJPq5I-pG OT39jgRQ nU6dniG1 KwbOIwWPc4iy2cecGWNhJ5

KEnBAh4KIp7zee-7kj7RMUyDt3irrg3A-hbm7nbEWaI qXHuCp7lxMx6-w2vznk-2Jaf $\sim$ 5 5 54supUCN ou1Kn UoXJa7wmKcSIDxx1JHeg8 V6-LioFVP6 EacjhchIhv QjUNVeR3mMJ4vj572Q \&Key-Pair-Id=APKAJLOH F5GGSLRBV4ZA

12. Baixas, J. (2012). "Envolventes: La piel de los edificios". (pg.2-5) https://scielo.conicyt.cl/pdf/arq/n82/art16.pdf

13. López-Maroto, A. (2020) “Arquitectura Biomimética y Biomímesis" de: http://hdl.handle.net/10045/101905

14. Dabija, A. (2019) "Sustainability in Architectural Design: Smart Systems and Traditional Materials" . de: https://iopscience.iop.org/article/10.1088/1757-899X/60 3/3/032081/meta

15. Uriarte, J. (2020) "Información y Características: Cocodrilo". https://www.caracteristicas.co/cocodrilo/\#ixzz6dVA7pa $\underline{\mathrm{Xm}}$

16. Irene H. Chen, Wen Yang, Marc A. Meyers (2014) "Alligator osteoderms: Mechanical behavior and hierarchical structure". Materials Science and Engineering: C, Volume 35, pgs 441-448, ISSN 0928-4931, https://doi.org/10.1016/i.msec.2013.11.024

17. Froeschle L.M. (1999) "Environmental Assessment and Specification of Green Building Materials, The Construction Specifier", p. 53-57.

18. Río Merino, Mercedes del (2005). Nuevas aplicaciones del corcho en el campo de la edificación. En: "III Encuentro Eurocork", 2005, Huelva. http://oa.upm.es/1896/1/RIO PON 2005 01.pdf

19. Figure1. García, A. (2019) “Arquitectura Bioclimática, ¿Un concepto pasado de moda?". de: https://www.seiscubos.com/blog/vigencia-arquitectura-b ioclimatica

20. Figure 2. López-Maroto, A. (2020) “Arquitectura Biomimética y Biomímesis" de: http:/hdl.handle.net/10045/101905

21. Figure 3. Brown, G. Z., \& DeKay, M. (2001). Sun, wind $\&$ light: Architectural design strategies. New York: Wiley.

22. Figure 4. Boyd, S. (2006) "Siamese Crocodile Survey and Monitoring Handbook Fauna \& Flora International In association with the Forestry Administration and Mekong Wetlands Biodiversity Conservation and Sustainable Use Programme". https://www.researchgate.net/figure/Diagram-of-crocodi le-showing-neck-scales-nostrils-eyes-ears-webbed-feetand-armoured fig4 271131665

23. Figure 5. Pristis, H. (2011)"The Fossil Fourum" http://www.thefossilforum.com/index.php?/gallery/imag e/17509-crocodilian-osteoderms/

24. Figura 6. Aurastock. Image ID:24512479. https://www.vectorstock.com/royalty-free-vector/crocod ile-skin-gray-and-white-seamless-pattern-vector-245124 $\underline{79}$

25. Figure 7. Uriarte, J. (2020) "Cocodrilo". Para:

Caracteristicas.co.

https://www.caracteristicas.co/cocodrilo/ 